07

\title{
Изучение влияния легирования никелем кремниевых солнечных элементов с глубоким $p-n$-переходом
}

\author{
() М.К. Бахадырханов ${ }^{1}$, С.Б. Исамов ${ }^{1}$, 3.Т. Кенжаев ${ }^{2}$, С.В. Ковешников ${ }^{1}$ \\ ${ }^{1}$ Ташкентский государственный технический университет, Ташкент, Узбекистан \\ ${ }^{2}$ Каракалпакский государственный университет, Нукус, Узбекистан \\ E-mail: bahazeb@yandex.com
}

Поступило в Редакцию 3 июня 2019г.

В окончательной редакции 11 июня 2019г.

Принято к публикации 13 июня 2019 г.

\begin{abstract}
Показано, что легирование лицевой стороны солнечного элемента с глубоко залегающим $p-n$-переходом атомами никеля приводит к увеличению значений плотности тока короткого замыкания $J_{s c}$ на $89 \%$ и напряжения холостого хода $V_{o c}$ на $19.7 \%$. Дополнительная термообработка при $700^{\circ} \mathrm{C}$ в течение часа приводит к росту $J_{s c}$ на $98.4 \%$ и $V_{o c}$ на $13.18 \%$. Предполагается, что рост эффективности преобразования инфракрасного излучения происходит за счет формирования кластеров атомов никеля, являющихся геттерирующими центрами для неконтролируемых рекомбинационных примесей.
\end{abstract}

Ключевые слова: фотоэлемент, кремний, никель, легирование, термоотжиг, кластеры, коэффициент собирания, время жизни.

DOI: 10.21883/PJTF.2019.19.48307.17902

Одним из основных параметров фотодиодов и вентильных фотоэлементов является коэффициент собирания $(\eta)$ фотогенерированных носителей заряда. Этот параметр в основном зависит от показателя поглощения кремния (с учетом его сильной спектральной зависимости), глубины залегания $p-n$-перехода $(L)$ и диффузионной длины неосновных носителей заряда $(l=\sqrt{D \tau})$. Для обеспечения максимального значения $\eta$ необходимо выполнение условия $l>L[1-5]$. В современных эффективных фотоэлементах глубина $p-n$ перехода составляет $L=0.3-0.5 \mu \mathrm{m}$, что оптимально для видимой и ультрафиолетовой части солнечного излучения. Однако при этом существенно уменьшается количество поглощенных вблизи $p-n$-перехода квантов инфракрасного и красного видимого спектра Солнца, что уменьшает коэффициент собирания. Инфракрасные лучи поглощаются в глубине базы, а генерированные носители в значительной части рекомбинируют. Поэтому представляет большой интерес разработать способ создания (формирования) такой структуры солнечного элемента, которая позволит повысить их эффективность в области инфракрасного спектра.

В настоящей работе приводятся результаты исследования дополнительного легирования атомами никеля кремниевых фотоэлементов с глубоким $p-n$-переходом.

Показано, что дополнительное легирование никелем кремниевых $p-n$-структур позволяет создать фотоэлементы с большей эффективностью в ИК-области спектра.

Исходные $p-n$-структуры создавались посредством диффузии фосфора при $T=1280^{\circ} \mathrm{C}$ в течение $t=5 \mathrm{~h}$ в кремниевых пластинах $p$-типа (диаметр $76 \mathrm{~mm}$ ) с удельным сопротивлением $0.5 \Omega \cdot \mathrm{cm}$ (КДБ-0.5). При этом формировался достаточно глубокий $p-n$-переход с высокой поверхностной концентрацией фосфора. За счет глубокого залегания $p-n$-перехода у этих образцов сильно снижена чувствительность в ультрафиолетовой и видимой области спектра и ослаблено влияние поверхностной рекомбинации дырок на лицевой стороне солнечного элемента, что происходит из-за наличия значительного градиента концентрации фосфора. Такой выбор исходных образцов определялся тем, что их параметры зависят преимущественно от времени жизни неосновных носителей и коэффициента поглощения света в базе.

Глубина $p-n$-перехода в образцах составляла $L=29-30 \mu \mathrm{m}$ (определялась послойным шлифованием и измерением слоевого сопротивления четырехзондовым методом). При этом концентрация электроактивной части примеси фосфора $\left(N \sim(1-2) \cdot 10^{20} \mathrm{~cm}^{-3}[6,7]\right)$ на поверхности соответствовала случаю предельной растворимости фосфора при температуре диффузии, а расчетная высота барьера $p-n$-перехода $\varphi=0.97 \mathrm{eV}$.

Затем полученные пластины разрезались на отдельные образцы размером $1 \times 1 \mathrm{~cm}$ и подвергались соответствующей механической обработке и химической очистке. Для всех образцов (без защитных слоев и с индий-галлиевыми контактами) при одинаковых условиях были определены напряжение холостого хода $V_{o c}$ и плотность тока короткого замыкания $J_{s c}$. Параметры исследуемых структур были измерены при освещении лампой накаливания при плотности мощности около $150 \mathrm{~mW} / \mathrm{cm}^{2}$. Эти параметры были достаточно низкими $\left(J_{s c} \sim 2.7-2.8 \mathrm{~mA} / \mathrm{cm}^{2}, V_{o c} \sim 370-380 \mathrm{mV}\right)$ из-за глубокого залегания $p-n$-перехода. Затем эти образцы делились на три группы для получения разных структур (структуры показаны на рисунке). Группа I - контроль- 


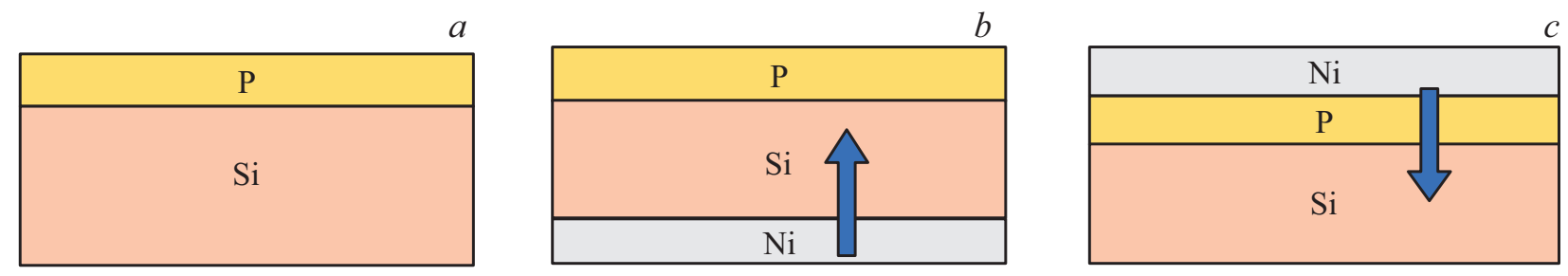

Разновидности структур типа I $(a)$, II $(b)$, III $(c)$.

Таблица 1. Средние значения $V_{o c}$ и $J_{s c}$ для образцов различных групп, а также изменение $V_{o c}$ и $J_{s c}$ групп II и III относительно параметров группы I

\begin{tabular}{l|c|c|c}
\hline \multirow{2}{*}{ Параметр } & Группа I (контрольные образцы $)$ & \multicolumn{1}{|c}{ Группа II } & \multicolumn{1}{|c}{ Группа III } \\
\cline { 2 - 4 } & После термоотжига $\left(1200^{\circ} \mathrm{C}, 1 \mathrm{~h}\right)$ & \multicolumn{2}{|c}{ После диффузии Ni $\left(1200^{\circ} \mathrm{C}, 1 \mathrm{~h}\right)$} \\
\hline$J_{s c}, \mathrm{~mA} / \mathrm{cm}^{2}$ & 2.7 & 4.86 & 5.1 \\
$\Delta J_{s c} / J_{s c}, \%$ & - & 450 & 89 \\
$V_{o c}, \mathrm{mV}$ & 380 & 18.4 & 455 \\
$\Delta V_{\text {oc }} / V_{o c}, \%$ & - & 1.737 & 19.7 \\
$P_{\text {peak }}, \mathrm{mW} / \mathrm{cm}^{2}$ & 1.026 & 69.3 & 2.320 \\
$\Delta P_{\text {peak }} / P_{\text {peak }}, \%$ & - & & 126
\end{tabular}

Примечание. $\Delta J_{s c} / J_{s c}$ - изменение плотности тока короткого замыкания относительно значений для контрольных образцов; $\Delta V_{o c} / V_{o c}-$ изменение напряжения холостого хода относительно значений для контрольных образцов; $P_{\text {peak }}-$ удельная пиковая мощность (вычисляется как произведение $J_{s c}$ на $\left.V_{o c}\right) ; \Delta P_{p e a k} / P_{p e a k}$ - изменение удельной пиковой мощности относительно значений для контрольных образцов.

ные образцы; группа II - образцы, у которых на тыльной ( $p$-стороне) структур в вакууме был напылен тонкий металлический слой чистого никеля толщиной $1 \mu \mathrm{m}$; группа III - металлическая пленка никеля создавалась на поверхности диффузионного $n$-слоя.

Все образцы подвергались диффузионному термоотжигу в одинаковых условиях при $T=1200^{\circ} \mathrm{C}, t=1 \mathrm{~h}$. После этого была проведена химическая обработка, чтобы снять оксид кремния с поверхности. При этом во всех группах образцов за счет разгонки глубина $p-n$-перехода увеличилась до $L=30 \pm 3 \mu \mathrm{m}$. В группе II образцов за счет диффузии никеля (у него очень высокий коэффициент диффузии $[8,9])$ объем образца легировался практически однородно, и только поверхностный слой (толщиной $2-3 \mu \mathrm{m}$ ) области $p$-типа материала оставался обогащенным атомами никеля, что было установлено методом косого шлифа и путем проверки прозрачности на инфракрасном микроскопе „ИНФРАМ-И“. Известно, что концентрация никеля в приповерхностном слое может достигать $N \sim 10^{20} \mathrm{~cm}^{-3}$ [8], что позволяет надеяться на существенное улучшение рекомбинационных свойств базы солнечного элемента и, возможно, фотоактивного поглощения в ИК-области спектра в этом слое. Поскольку в солнечном элементе использовался очень глубоко залегающий $p-n$-переход, фактически исследовалось влияние легирования никелем только на чувствительность в ИК-области спектра. В группе III образцов обогащенный никелем поверхностный слой образовывался в слое $n$-типа (лицевом слое солнечного элемента). Затем при одинаковых условиях измерялись значения $J_{s c}$ и $V_{o c}$ во всех образцах.

В табл. 1 представлены средние значения $V_{o c}$ и $J_{s c}$ для каждой группы образцов. Как видно из этой таблицы, в образцах группы II значение $V_{o c}$ увеличивается $18.4 \%$ (относительно среднего значения $V_{o c}$ группы I), а значение $J_{s c}$ увеличивается более заметно (на $43 \%$ ), т.е. наблюдается заметное улучшение параметров.

В образцах группы III наблюдается еще более заметное улучшение параметров. В них среднее значение $V_{o c}$ по отношению к таковому для группы I увеличивается на $19.7 \%$, а $J_{s c}-$ на $89 \%$.

На основе полученных результатов можно утверждать, что дополнительное легирование примесными атомами никеля приводит к улучшению параметров $V_{o c}$ и $J_{s c}$, при этом наиболее существенный рост наблюдается в образцах группы III.

Далее все три группы образцов подвергались термообработке в течение часа при температурах $T=700$, $800,900,1000$ и $1100^{\circ} \mathrm{C}$. После снятия оксидной пленки измерялись $V_{o c}$ и $J_{s c}$ (в тех же условиях, что и до термообработки). В табл. 2 представлены результаты только для образцов групп II и III, отожженных при $T=700$ и $800^{\circ} \mathrm{C}$, так как именно при этих температурах наблюдается существенное изменение параметров.

Как видно из табл. 2, параметры образцов группы II при дополнительном отжиге изменялись в сторону улучшения. При температуре отжига $700^{\circ} \mathrm{C} J_{s c}$ увеличивается по сравнению с величиной до отжига на $97.4 \%$, а $V_{o c}$ - на $12.2 \%$. Отжиг при $T=800^{\circ} \mathrm{C}$ привел к росту 
Таблица 2. Средние значения параметров образцов групп II и III после дополнительной термообработки при $T=700$ и $800^{\circ} \mathrm{C}$ и их изменение относительно параметров до отжига

\begin{tabular}{l|c|c|c|c}
\hline \multirow{2}{*}{ Параметр } & \multicolumn{2}{|c|}{ Группа II } & \multicolumn{2}{c}{ Группа III } \\
\cline { 2 - 5 } & $700^{\circ} \mathrm{C}$ & $800^{\circ} \mathrm{C}$ & $700^{\circ} \mathrm{C}$ & $800^{\circ} \mathrm{C}$ \\
\hline$J_{s c}, \mathrm{~mA} / \mathrm{cm}^{2}$ & 7.62 & 6.22 & 10.12 & 9.5 \\
$\Delta J_{s c} / J_{1 s c}, \%$ & 97.4 & 61 & 98.4 & 86.27 \\
$V_{o c}, \mathrm{mV}$ & 505 & 510 & 515 & 520 \\
$\Delta V_{\text {oc }} / V_{1 o c}, \%$ & 12.2 & 13.3 & 13.18 & 14.28 \\
$P_{\text {peak }}, \mathrm{mW} / \mathrm{cm}^{2}$ & 3.848 & 3.172 & 5.212 & 4.940 \\
$\Delta P_{\text {peak }} / P_{1 \text { peak }}, \%$ & 121.5 & 82.6 & 129 & 113
\end{tabular}

Примечание. $\Delta J_{s c} / J_{1 s c}-$ изменение плотности тока короткого замыкания относительно значений до термообработки; $\Delta V_{o c} / V_{1 o c}-$ изменение напряжения холостого хода относительно значений до термообработки; $P_{\text {peak }}$ - удельная пиковая мощность (вычисляется как произведение $J_{s c}$ на $\left.V_{o c}\right) ; \Delta P_{p e a k} / P_{1 p e a k}-$ изменение удельной пиковой мощности относительно значений до термообработки.

$J_{s c}$ на $61 \%$, а $V_{o c}$ - на $13.3 \%$. Для этих образцов термоотжиг при $T=700^{\circ} \mathrm{C}$ является более эффективным, чем при $T=800^{\circ} \mathrm{C}$.

Очень хорошие результаты были получены на образцах группы III: значение $J_{s c}$ после отжига при $T=700^{\circ} \mathrm{C}$ увеличивается по сравнению с величиной до отжига на $98.4 \%$, а значение $V_{o c}$ растет на $13.18 \%$. Аналогично после отжига при $T=800^{\circ} \mathrm{C}$ значение $J_{s c}$ повышается на $86.27 \%$, а $V_{o c}-$ на $14.28 \%$. Таким образом, для образцов группы III термоотжиг при $T=700$ и $800^{\circ} \mathrm{C}$ приводит к существенному изменению $V_{o c}$ и $J_{s c}$.

Чтобы установить оптимальные параметры дополнительной термообработки, проводился термоотжиг при $T=700$ и $800^{\circ} \mathrm{C}$ в течение $t=2,3$ и $5 \mathrm{~h}$. Как показали результаты эксперимента, увеличение времени термоотжига вначале практически не влияет на параметры $V_{o c}$ и $J_{s c}$, но более длительный отжиг $(t>3 \mathrm{~h})$ приводит к ухудшению $V_{o c}$ и $J_{s c}$ во всех образцах.

Таким образом, установлено, что для солнечных элементов с достаточно глубоким $p-n$-переходом легирование примесными атомами никеля с дальнейшей дополнительной термообработкой позволяет существенно улучшить их основные параметры.

В работах $[10,11]$ показано, что примесные атомы никеля в решетке кремния создают нано- и микрокластеры. Размеры, концентрация, структура и состав таких кластеров в основном определяются температурой дополнительного отжига и общей концентрацией введенных в кремний атомов никеля. На основе результатов этих работ можно утверждать, что в образцах групп II и III атомы никеля распределяются равномерно по всему объему базы солнечного элемента с концентрацией $\sim 10^{18} \mathrm{~cm}^{-3}$, а также образуют кластеры, являющиеся стоками для рекомбинационных примесей. Это может привести к существенному снижению концентрации различных рекомбинационных центров и увеличению времени жизни неосновных носителей заряда, в первую очередь за счет формирования нано- и микрокластеров атомов никеля в приповерхностных слоях, имеющих высокую концентрацию никеля и кислорода. Как показано в [12,13], атомы никеля геттерируются атомами растворенного в кремнии кислорода с образованием кластеров, содержащих кроме никеля значительные концентрации кислорода, кремния и различных рекомбинационных примесей. Увеличение времени жизни неосновных носителей заряда в базе может объяснить рост параметров образцов групп II и III. Однако этот механизм не объясняет рост параметров образцов группы III относительно параметров образцов группы II, так как влияние геттерирующего рекомбинационные примеси слоя не зависит от места его расположения (на лицевой или тыльной стороне солнечного элемента). Это позволяет предположить наличие еще одного механизма улучшения параметров.

Мы предполагаем, что легирование кластерами никеля может увеличивать коэффициент поглощения базы солнечного элемента в инфракрасной области спектра за счет возникновения плазмонного резонанса, что приводит к лучшему совмещению области поглощения ИК-света с $p$-n-переходом и повышает коэффициент собирания носителей. Это косвенно подтверждается тем, что образцы, легированные никелем, при изучении их в инфракрасных лучах ИК-микроскопа имеют визуально больший коэффициент поглощения. Бо́льшая эффективность ,лицевого“ легирования (образцы группы III) также косвенно указывает на увеличение роли оптического поглощения. Подтверждение или опровержение этой гипотезы требует дополнительных исследований.

Таким образом, формирование обогащенного никелем слоя в приповерхностной области вблизи $p-n$-перехода открывает новые возможности для создания кремниевых фотоэлементов с повышенной эффективностью в инфракрасной области солнечного спектра.

\section{Финансирование работы}

Работа выполнена в рамках проекта ОТ-Ф2-50 „Разработка научных основ формирования элементарных ячеек AIIBVI и AIIIBV в решетке кремния - новый подход в получении перспективных материалов для фотоэнергетики и фотоники“.

\section{Конфликт интересов}

Авторы заявляют, что у них нет конфликта интересов.

\section{Список литературы}

[1] Фукс Б.И. // ФТП. 2014. Т. 48. В. 12. С. 1704-1712.

[2] Миличко В.А., Шалин А.С., Мухин И.С., Ковров А.Э., Красилин А.А., Виноградов А.В., Белов П.А., Симовский К.Р. // УФН. 2016. Т. 186. № 8. С. 801-852. 
[3] АЯанасев В.П., Теруков Э.И., Шерченков А.А. Тонкопленочные солнечные элементы на основе кремния. 2-е изд. СПб.: Изд-во СПбГЭТУ „ЛЭТИ“, 2011. 168 с.

[4] Лунин Л.С., Лунина М.Л., Пащенко А.С., Алфимова Д.Л., Арустамян Д.А., Казакова А.Е. // Письма в ЖТФ. 2019. T. 45. B. 6. C. 7-9.

[5] Гук Е.Г., Зимогорова Н.С., Швари, М.З., Шуман В.Б., Токранова Н.А. // Письма в ЖТФ. 1995. Т. 21. В. 2. C. $40-44$.

[6] Болтакс Б.И. Диффузия и точечные дефекты в полупроводниках. Л.: Наука, 1972. 384 с.

[7] König D., Gutsch S., Gnaser H., Wahl M., Kopnarski M., Göttlicher J., Steininger R., Zacharias M., Hiller D. // Sci. Rep. 2015. V. 5. P. 9702. DOI: $10.1038 /$ srep09702

[8] Lindroos J., Fenning D.P., Backlund D.J., Verlage E., Gorgulla A., Estreicher S.K., Savin H., Buonassisi T. // J. Appl. Phys. 2013. V. 113. N 20. P. 204906.

[9] Астащенков А.С., Бринкевич Д.И., Петров В.В. // Докл. БГУИР. 2018. № 8 (38). С. 37-43.

[10] Bakhadyrkhanov M.K., Iliyev Kh.M., Ayupov K.S., Abdurakhmanov B.A., Krivenko P.Yu., Kholmukhamedov R.L. // Inorgan. Mater. 2011. V. 47. N 9. P. 962-964.

[11] Abdurakhmanov B.A., Bakhadirkhanov M.K., Ayupov K.S., Iliyev H.M., Saitov E.B., Mavlyanov A., Kamalov H.U. // Nanosci. Nanotechnol. 2014. V. 4. N 2. P. 23-26.

[12] Bakhadyrkhanov M.K., Ismailov K.A., Ismaylov B.K., Saparniyazova Z.M. // SPQEO. 2018. V. 21. N 4. P. 300-304.

[13] Bakhadyrhanov M.K., Sodikov U.X., Melibayev D., Wumaier T., Koveshnikov S.V., Khodjanepesov K.A., Zhan J. // J. Mater. Sci. Chem. Eng. 2018. V. 6. P. 180-190. 